\title{
Toward More Uniform Conflict Disclosures: The Updated ICMJE Conflict of Interest Reporting
} Form

The great variability in the processes that different journals use to ask about and report authors' potential conflicts of interest creates confusion for authors, readers, and the public. To help lessen this confusion, the International Committee of Medical Journal Editors (ICMJE) developed an electronic uniform disclosure form and placed it in the public domain in October 2009. The ICMJE member journals piloted the form, encouraged other journals to use it, and invited feedback. We recognized that the reporting of competing interests is complex and nuanced and sometimes contentious, and thus anticipated modifying the form on the basis of feedback received. We are grateful to the many authors, editors, and other interested parties who took the time to comment on the form and its implementation. The issues raised ranged from technical problems about the correct deployment of the form (to function, it requires the user to download the free Adobe Reader, version 8.0 or higher [Adobe Systems, San Jose, California]) to concerns about the ethics of inquiring about nonfinancial associations. The Committee considered these valuable comments and revised the form at our most recent meeting.

We made several modifications. The major change in the reporting instrument is the removal of the queries about potential competing interests of authors'spouses and minor children and about nonfinancial competing interests. We made this change on the basis of the largely negative feedback that we received about these sections. People who commented about this issue made it clear that there is immense difficulty in defining competing interests beyond those that involve the direct exchange of money from an interested party to an individual author or the author's institution. Because the Committee continues to believe that there are situations in which indirect or nonfinancial factors could influence (or appear to influence) the conduct or interpretation of work, we replaced the specific questions with a single open-ended query (new Section 4) that asks, "Are there any other relationships or activities that readers could perceive to influence, or that give the appearance of potentially influencing, what you wrote in the submitted work?"This change places the onus on the person completing the form to identify and report appropriate nonfinancial competing interests. It has the advantage of being less intrusive than the previous queries, while providing a locus where authors can report nonfinancial relationships that may be perceived as potential conflicts of interest.

In response to comments about the clarity of the form, each field in the form now has a numeric designation. We have modified the language in the instructions and in the individual queries. To make the form more useful to nonnative English speakers, we are creating a glossary of terms used in the form and will be posting guidelines for translation of the form's instructions into multiple languages. The translation of this form is particularly challenging because translations must capture the essence of the queries rather than their literal meaning. The glossary and instructions will be available at www.icmje.org in the next few months; translations will be posted on the ICMJE Web site as they become available.

The new form, in English, is currently available on the ICMJE Web site and the Web sites of our member journals. Authors who have completed the older version of the form in conjunction with a journal submission need not complete the new form, but the new form will be the standard for new submissions. We welcome continued input from the user community. Comments can be sent via the "contact us" link at www.icmje.org. The Committee will consider comments received before 1 May 2011, when we prepare the next iteration of the uniform conflict of interest disclosure form.

The complexity, subjectivity, and emotionality of conflict disclosure assure that some will consider this 
vehicle for reporting to be excessively burdensome, while others will think it falls short in one area or another. We cannot, however, let the perfect be the enemy of the good. We hope that the revised ICMJE form will be another step toward simplifying and standardizing reporting of conflicts of interest. A more uniform reporting process will alleviate the confusion that prevails when multiple journals use different reporting formats and ease the reporting burden on the members of the biomedical research community so they can pursue the research that will improve the care that we can deliver to our patients. With these thoughts in mind, we encourage all journals to adopt the new version of the uniform disclosure form.

Jeffrey M. Drazen

Editor-in-Chief, New England Journal of Medicine

Peter W. de Leeuw

Editor-in-Chief, Nederlands Tijdschrift voor Geneeskunde (Dutch Journal of Medicine)

Christine Laine

Editor, Annals of Internal Medicine

Cynthia Mulrow

Secretary, ICMJE

Senior Deputy Editor, Annals of Internal Medicine

Catherine D. DeAngelis

Editor-in-Chief, JAMA

Frank A. Frizelle

Editor-in-Chief, The New Zealand Medical Journal

Fiona Godlee

Editor-in-Chief, BMJ

\section{Charlotte Haug}

Editor-in-Chief, Tidsskrift for Den norske legeforening (Journal of the Norwegian Medical Association)
Paul C. Hébert

Editor-in-Chief, Canadian Medical Association Journal

\section{Astrid James}

Deputy Editor, The Lancet

\section{Sheldon Kotzin}

Associate Director for Library Operations, National Library of Medicine

Ana Marušić

Editor-in-Chief, Croatian Medical Journal

Humberto Reyes

Editor, Revista Médica de Chile

Jacob Rosenberg

Editor, Journal of the Danish Medical Association

\section{Peush Sahni}

Representative and Past President, World Association of Medical Editors

\section{Martin B. Van Der Weyden}

Editor, The Medical Journal of Australia

\section{Getu Zhaori}

Editor-in-Chief, Chinese Medical Journal

Note: This editorial is being published simultaneously in all ICMJE member journals.

Disclaimer: Dr Sahni's affiliation as representative and past president of the World Association of Medical Editors (WAME) does not imply endorsement by WAME member journals that are not part of the ICMJE. 